\title{
Testing the Option Value Theory of Irreversible Investment
}

Tarek M. Harchaoui, Pierre Lasserre

\section{Série Scientifique \\ Scientific Series}

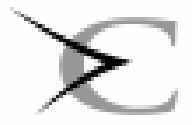

Centre internaiversinaire de recterche

Montréal

Octobre 1999 


\section{CIRANO}

Le CIRANO est un organisme sans but lucratif constitué en vertu de la Loi des compagnies du Québec. Le financement de son infrastructure et de ses activités de recherche provient des cotisations de ses organisationsmembres, d'une subvention d'infrastructure du ministère de la Recherche, de la Science et de la Technologie, de même que des subventions et mandats obtenus par ses équipes de recherche.

CIRANO is a private non-profit organization incorporated under the Québec Companies Act. Its infrastructure and research activities are funded through fees paid by member organizations, an infrastructure grant from the Ministère de la Recherche, de la Science et de la Technologie, and grants and research mandates obtained by its research teams.

\section{Les organisations-partenaires / The Partner Organizations}

-École des Hautes Études Commerciales

-École Polytechnique

- Université Concordia

- Université de Montréal

-Université du Québec à Montréal

-Université Laval

-Université McGill

-MEQ

-MRST

-Alcan Aluminium Ltée

- Banque Nationale du Canada

-Bell Québec

-Développement des ressources humaines Canada (DRHC)

-Egis

-Fédération des caisses populaires Desjardins de Montréal et de l'Ouest-du-Québec

-Hydro-Québec

-Imasco

- Industrie Canada

- Microcell Labs inc.

- Raymond Chabot Grant Thornton

- Téléglobe Canada

-Ville de Montréal

(C) 1999 Tarek M. Harchaoui et Pierre Lasserre. Tous droits réservés. All rights reserved. Reproduction partielle permise avec citation du document source, incluant la notice $\odot$.

Short sections may be quoted without explicit permission, provided that full credit, including @ notice, is given to the source.

Ce document est publié dans l'intention de rendre accessibles les résultats préliminaires de la recherche effectuée au CIRANO, afin de susciter des échanges et des suggestions. Les idées et les opinions émises sont sous l'unique responsabilité des auteurs, et ne représentent pas nécessairement les positions du CIRANO ou de ses partenaires.

This paper presents preliminary research carried out at CIRANO and aims at encouraging discussion and comment. The observations and viewpoints expressed are the sole responsibility of the authors. They do not necessarily represent positions of CIRANO or its partners.

\section{ISSN 1198-8177}




\title{
Testing the Option Value Theory of Irreversible Investment ${ }^{*}$
}

\author{
Tarek M. Harchaoui ${ }^{\dagger}$, Pierre Lasserre ${ }^{\ddagger}$
}

\section{Résumé / Abstract}

Nous établissons par la méthode des actifs contingents la valeur de l'option d'effectuer des investissements irréversibles réels qui sont sensibles aux paramètres économiques prévalant au moment de la décision. Nous testons ensuite si des mines de cuivre canadiennes choisissent bien d'effectuer leurs investissements en capacité de production au moment où le prix du cuivre atteint le niveau critique impliqué par la théorie. Les résultats sont fortement en faveur de celle-ci. Le modèle explique tant la taille que la date des investissements d'une manière statistiquement et économiquement satisfaisante; des simulations avec un processus de retour à la moyenne indiquent que ces résultats ne dépendent pas de façon cruciale de l'hypothèse que le prix suit un processus Brownien géométrique.

This paper statistically tests the option theory of irreversible investment under uncertainty. Using contingent claims valuation, we derive the value of options to invest in capacity, where the projects are endogenous to the economic circumstances prevailing at the investment date. We then test whether capacity investment decisions made by Canadian copper mines are compatible with the trigger price implied by the theory. The results speak strongly in favor of option theory as a theory of real investment. Our model explains both investment size and timing satisfactorily, from a statistical, and from an economic, point of view, and numerical simulations with a mean-reverting process suggest that the results do not depend crucially on the price being assumed to follow a geometric Brownian motion.

Mots Clés : Investissement irréversible, incertitude, actifs contingents, valeur d'option, modèle «Putty Clay », investissement réel, prix critique

Keywords: Irreversible investment, uncertainty, contingent claims, option value, Putty Clay, real investment, trigger price

JEL: D92, G1, L72, Q31

\footnotetext{
* Corresponding Author: Pierre Lasserre, CIRANO, 2020 rue University, 25 ${ }^{\text {ème }}$ étage, Montréal, Qc, Canada H3A 2A5 Tél. : (514) 985-4011 Fax : (514) 985-4039 courriel : lasserrp@ cirano.umontreal.ca We thank Marcel Dagenais, Phil Merrigan, Harry Paarsch, Pierre Perron, and Robert Pindyck for comments on an earlier version of the paper. We also thank the participants in the Batterymarch Finance Seminar at the Sloan School of Management, the Finance Seminar at HEC (Paris), and the IDEI-CREMAQ Seminar at Toulouse, as well as anonymous referees, for their comments. Financial support from the SSHRCC is gratefully acknowledged.

$\dagger$ Statistics Canada

* Université du Québec à Montréal and CIRANO
} 


\section{INTRODUCTION}

Much of the economic literature on investment has focused on incremental investment in a neoclassical framework. With notable exceptions such as the seminal works of Arrow (1968) and Henri (1974), and the strand of papers in the environment literature following Arrow and Fisher (1974), this literature generally ignores irreversibilities. More recently, the theory of option pricing has been brought to bear in the area of real investment. It was shown that irreversible investment opportunities may be viewed as options and valued accordingly, and that similar rules as govern the exercise of options may be applied to real investment decisions. While this new literature has been successful and innovative in modeling real investment decisions, and while many simulations have contributed to illustrate its implications, it has not been tested in a statistical sense, and it still has to make a dent in the econometrics of investment. Our paper is a step in that direction. We provide a test of option theory applied to real investment, and, in the process, we actually estimate econometrically both the magnitude and the timing of irreversible investments.

Natural resources provide an impressive series of contributions to the real option literature. Tourinho (1979), later followed by Paddock, Siegel and Smith (1988), modeled the value of natural resource reserves under uncertainty as an option to extract the resource in the future; Brennan and Schwartz (1985) showed how to value an option to invest in a mine and established the companion investment rule. Mackie-Mason (1990) cast the option pricing model into a framework involving the non linear taxation of mining firms. But, as the survey by Pindyck (1991) and the book by Dixit and Pindyck (1994) make clear, even more papers are now unrelated to natural resource investments. To mention some of the most relevant to our purpose, Pindyck (1988) investigated capacity investment as a compounded set of options while Majd and Pindyck (1987) modeled the 'time to build' as a process in which a firm invests continuously until the completion of a project, each expenditure buying it an option to spend the next dollar. 
Besides illustrating the numerous implications of option theory to real investment, this literature cast a serious doubt on the validity of alternative, more traditional, theories. It showed that irreversibility affects investment rules in a fundamental way: by undertaking an irreversible investment, a firm gives up the possibility to use new information that might arrive later on (Bernanke, 1983). As stressed by Ingersoll and Ross (1992) and McDonald and Siegel (1986), this invalidates the Net Present Value (NPV) rule of investment.

The strong implications of option theory to the realm of real investment underline the urgency of empirical tests. Here, however, the literature is still in its infancy. According to Dixit and Pindyck (1994, p. 483), 'Given the difficulties (...), it is not surprising that there have been few attempts to statistically test the theory of irreversible investment under uncertainty.' A few papers focus on various qualitative implications of the theory: return volatility in the case of Pindyck and Solimano (1993), Leahy and Whited (1996), or Bell and Campa (1997); the waiting period in the case of Hurn and Wright (1994); the presence of an option premium in the case of Quigg (1993). In this paper, we focus on the threshold that triggers investment, overcoming the obstacle encountered by Caballero and Pindyck (1996) that the trigger price cannot be observed directly, and recognizing that project characteristics are endogenous.

Thus the work presented here uses option theory to derive the value of capacity investment projects, where the projects are endogenous to the economic circumstances prevailing at the investment date. Knowing the value of the option to invest, firms compute a threshold value for the project, and decide on investment dates by comparing current project value with the threshold. Our results speak strongly in favor of option theory as a theory of real investment. The model explains investment behavior satisfactorily, both from a statistical, and from an economic, point of view. It also illustrates how option premia affect investment timing.

A number of simplifying assumptions are made and we try to check the sensitivity of our results to some of them. Perhaps the major one is that we focus on the price of output (copper) as single source of uncertainty. While this is a wild simplification, we 
believe that it preserves the essence of capacity investment decisions in the copper mining industry: once a deposit has been ascertained, the uncertainty surrounding output prices exceeds by far uncertainty on factor prices, the technology, or available ore reserves. Another strong assumption made in our paper is that firms lose all flexibility when they make their initial capacity investment. In reality, firms still have a number of options left open at that stage, such as shut-down and expansion options; in fact Slade (1997) focuses on such alternatives. However we believe that the decision to go ahead with a development is a major commitment whatever happens next, and we focus on that decision.

The paper is organized as follows. In Section 2, we present the capacity investment model, taking the investment date as given; this model allows us to compute the project value. The option to invest is based on the underlying project; its valuation is presented in Section 3. In Section 4, we present the econometric model, the data set and the estimation procedure, while Section 5 discusses the results and concludes.

\section{CAPACITY INVESTMENT AND PROJECT VALUE}

Capacity investments by mines provide a good example of irreversible investment under uncertainty. In fact, there is evidence that the 'Putty Clay' model of investment performs well in explaining capacity levels at Canadian mines (Lasserre, 1985; Harchaoui and Lasserre, 1995), although that model fails to explain the dates at which such investments are undertaken. The option model, on the other hand, focuses on timing, taking the characteristics of the project as given. We use a simple version of the 'Putty Clay' model in order to endogenize the characteristics of the investment project which will be used in the option model presented further below.

Let $S$ be the date at which a capacity investment project is completed and production is reported to start up. In such projects, construction typically takes from two to four years (Conrad and Hools, 1980); although construction duration is to some extent endogenous, we assume that, at some time $s$ during the construction period, a final deci- 
sion is made on capacity, based on information available at that time; then construction proceeds for another period $c$ until start-up. Under that assumption, the capacity observed at $S$ is based on information available at the decision date $s$, with $s=S-c(c$ is exogenous and identical across projects).

We treat $s$ as a choice variable further below. At this stage, however, let $s$ be exogenous and examine the value of the project at decision time as a function of economic, technological, and geological conditions observed at $s$. In order to focus on what we consider the key source of uncertainty, future output price, we assume that, at $s$, the firm knows its mineral reserves $R(s),{ }^{2}$ as well as the available technology, current and future factor prices, and the current and future tax systems. More specifically, we assume that real factor prices are non stochastic and rise at the common, constant, rate $\alpha_{w}$; and we assume that the current tax system is expected to remain unchanged.

Once the project is operational, ore reserves are transformed into metal or concentrate, whose real price at date $t, p(t)$, is assumed to follow a geometric Brownian motion

$$
\frac{d p(t)}{p(t)}=\alpha_{p} d t+\sigma d z
$$

The 'Putty Clay' assumption implies that ex ante, before $s$, the firm has a choice among a wide array of technologies and scales; ex post, once the investment has been realized, the firm must use the particular technology selected at $s$ : for any $t>s$, capacity and factor quantities are fixed. Productive capacity is maintained throughout the operating life. However, capital depreciates because of obsolescence and because major mining investments are highly mine specific and costly to transfer and adapt to other sites. Thus the project has no residual value at the end of its operating life.

We assume that mines produce at full capacity during their entire, uninterrupted,

\footnotetext{
${ }^{2}$ It is not uncommon for mines to delineate new reserves as exploitation proceeds. Thus the decision to invest creates options to expand. In our econometric work, we introduced dummy variables to distinguish between mine creations and expansions in our data set. They were not significant, which we interpret as meaning that expansion options do not affect capacity decisions significantly.
} 
operating life $T .^{3}$ Since the latter is constrained by available reserves, it follows (provided reserves are measured in the same units as output $Q$ ) that

$$
T=\frac{R(s)}{Q(s)}
$$

If a firm that discounts net real future revenues at rate $r$ undertakes a capacity investment at $s$, it selects an ex post technology (input mix and corresponding capacity) so as to maximize expected net cumulative revenues over its operating life. Since $Q$ is fixed and $p$ follows (1), the stream of discounted expected revenues may be integrated out over $T: E_{s}\left\{\int_{s}^{s+T} e^{-r t} p Q d t\right\}=p Q\left(1-e^{-\delta T}\right) / \delta$ where $\delta=r-\alpha_{p}$ is the discount rate applying to revenues, after correction for the drift in output price. The stream of variable costs may be integrated out in a similar way. Thus the net present value of the project at $s$ is, with all variables evaluated at $s$

$$
V=\max _{Q, T, L, K}\left\{a(T, \delta) p Q-a(T, \rho) w^{\prime} L-q K\right\}
$$

where $a(T, i)=\left(1-e^{-i T}\right) / i$ is the capitalization function giving the present value of a constant flow of $\$ 1$ over a period of $T$ when the rate of discount is $i ; \rho=r-\alpha_{w}$ is the discount rate applying to variable costs, after correction for their rate of growth; $L$ is the vector of variable factors, whose prices are $w ; q$ is the asset price of the capital $K$ sunk at $s$. All prices are tax corrected according to the regime prevailing at $s$ under the assumption that firms do not expect any change in the relevant future (see Harchaoui and Lasserre (1995) for details on the relevant taxation regimes).

\footnotetext{
${ }^{3}$ Mining projects are highly capital intensive. As a result, once a particular capacity investment has been realized, revenues cover variable costs by far; furthermore, variable costs cannot be entirely suppressed by temporarily closing down because of maintenance costs, long-term contractual arrangements, etc.; finally, there are substantial costs associated with starting up again a mine that closed down temporarily. As a result, it is highly unusual to observe mines shut down temporarily, or even simply reduce output substantially, in periods where prices are low. Although some gold mines, closed during the Bretton Woods era, reopened in the seventies, no such phenomenon ever occured with copper mines.
} 
Capacity investment projects may involve specific characteristics not taken into account in the foregoing analysis. We control for them by introducing the variables $X$ for geological characteristics; $G$ for ore grade; and $s$ for the state of technology at the time or the capacity decision ${ }^{4}$. Furthermore, it is immediate to show that $V$ is homogeneous of degree one in prices $(p, w, q)$, so that it can be rewritten, dividing all prices by the price of materials

$$
\begin{gathered}
V=w_{M} \max \left\{a(T, \delta) P Q-a(T, \rho) \sum_{i} W_{i} L_{i}-W_{K} K\right\} \\
\equiv w_{M} \tilde{V}\left(P, W_{l}, W_{E}, W_{K}, \delta, \rho, R, X, G, s\right)
\end{gathered}
$$

where $w_{M}$ is the price of materials; $P=p / w_{M} ; W_{i}=w_{i} / w_{M}$, for $i=l$ (labor), $E$ (energy); and $W_{k}=q / w_{M}$.

We assume that technological change is neutral and takes place at a constant rate $\gamma$, where neutrality means that $V(., s)=e^{\gamma\left[s-s^{\prime}\right]} V\left(., s^{\prime}\right)$, where all variables other than $s^{\prime}$ are evaluated at $s$. By $(4)$, this is $e^{\gamma\left[s-s^{\prime}\right]} w_{M}(s) \tilde{V}\left(., s^{\prime}\right)$ or, substituting $w_{M}(s)=$ $e^{\alpha_{w} s} w_{M}(0)$, choosing $s^{\prime}=0$, and choosing price indices so that $w_{M}(0)=1, V(., s)=$ $e^{\left[\alpha_{w}+\gamma\right] s} \tilde{V}(., 0)$. Consequently, the optimal expected project value at $s$ may be decomposed into the product of an exponential function of $s$ by a time-autonomous function of $P$ and $Z, v(P, Z) \equiv \tilde{V}(P, Z, 0)$, where $Z=W_{l}, W_{E}, W_{K}, \delta, \rho, R, X, G$ :

$$
V\left(p, w_{l}, w_{E}, w_{M}, q, \delta, \rho, R, X, G, s\right)=e^{\left[\alpha_{w}+\gamma\right] s} v(P, Z)
$$

Interpreting $V$ as a profit function, the capacity function $Q^{*}(P, Z, s)$ is obtained

\footnotetext{
${ }^{4}$ In some preliminary econometric investigations, we used location dummies (Ontario, Québec, Yukon) to account for geographical effects other than provincial differences in taxation, themselves embodied in the price variables; these dummies did not have any significant explanatory power. We also introduced dummies to distinguish between firms that are sampled once, twice, or three (four, five) times; they were not significant.
} 
from the version of Hotelling's lemma which applies in this context:

$$
Q^{*}(P, Z, s)=a\left(\frac{R}{Q^{*}}, \delta\right)^{-1} e^{\gamma s} \frac{\partial v(P, Z)}{\partial P}
$$

The next section is devoted to the evaluation of the option to undertake the project.

\section{THE OPTION MODEL APPLIED TO CAPACITY INVESTMENT}

Prior to the date $s$ of a capacity investment, a firm may be viewed as holding an option to invest into a project whose value $V$ evolves over time as prices change. If the theory is correct, the firm holds on to that call option in the years prior to $s$, and the option is actually exercised at $s$. Thus the model is a standard application of option theory. As such it emphasizes the timing of the investment decision, although the fact that we allow the stock of capital, proxied by capacity, to be endogenous, introduces into the model that traditional dimension of neoclassical investment models. However the model differs from traditional cost-of-adjustment models such as Abel (1985) in that no adjustment is possible ex post while there is full flexibility ex ante. The fact that our firm decides when to give up that flexibility also makes our model different from the model with partial irreversibility and expendability recently proposed by Abel et al. (1996) to examine the role of put and call options in investment decisions. In that two-period model, the firm chooses its capital stock in each period but has no flexibility with respect to the date that separates the two periods. Nonetheless, in both models, an increase in the value of a call option reduces the incentive to invest: in their model this means a lower capital stock; in our model, this means that the output price required to trigger investment is higher.

Evaluation of the option by contingent claims analysis requires the assumption that stochastic changes in the value of the project or the underlying asset may be spanned by existing assets. Here the underlying asset is copper concentrate, so that the spanning assumption does not seem unrealistic. Copper concentrate is an asset $x$ whose relative 
price equals $P$. The return on $x$ is made up of the change in $P$ and the unobserved convenience yield, which we treat as a residual variable ensuring the consistency of the model with data on the drift in $P$ and on rates of return (see Appendix).

The problem is to evaluate an option $\Pi(P, Z, t)$ giving the right to invest, at some uncertain date $s$ to be chosen in the future, into a project whose net current value at $s$ will be $v(P, Z) e^{\left[\alpha_{w}+\gamma\right] s}$. Applying the standard approach requires dealing with the fact that $\Pi$ is not time autonomous. We show in the appendix that the pseudo-option $\pi(P, Z) \equiv$ $\Pi(P, Z, t) e^{-\left[\alpha_{w}+\gamma\right] t}$ is autonomous and must satisfy the following homogeneous, seconddegree, differential equation in $P$ :

$$
\left[\rho_{f}-\gamma\right] \pi=\left[\alpha-\left[\tilde{r}-r_{f}\right]\right] P \pi_{P}+\frac{1}{2} \sigma^{2} P^{2} \pi_{P P}
$$

where $\alpha \equiv(1 / d t) E(d P / P)=\alpha_{p}-\alpha_{w} ; \tilde{r}$ is the risk-adjusted real rate of return; $r_{f}$ is the risk-free real rate of return; and $\rho_{f} \equiv r_{f}-\alpha_{w}$.

As shown in the appendix, the solution is $\pi(P, Z)=\beta P^{b}$ where $^{5}$

$$
b=\frac{1}{2}-\frac{\alpha-\left[\tilde{r}-r_{f}\right]}{\sigma^{2}}+\left[\left[\frac{\alpha-\left[\tilde{r}-r_{f}\right]}{\sigma^{2}}-\frac{1}{2}\right]^{2}+2 \frac{\rho_{f}-\gamma}{\sigma^{2}}\right]^{\frac{1}{2}}
$$

and where the trigger price $P^{*}$ and the parameter $\beta$ are defined by

$$
\begin{aligned}
\beta & =\frac{v\left(P^{*}, Z\right)}{P^{*^{b}}} \\
\beta b P^{*^{b-1}} & =v_{P}\left(P^{*}, Z\right)
\end{aligned}
$$

The solution can now be written in an empirically useful form. From (5), $v_{P}=$

\footnotetext{
${ }^{5} b$ must be greater than one.This requires $\rho_{f}-\gamma>\alpha-\left[\tilde{r}-r_{f}\right]$ i.e. $r_{f}-\alpha_{w}-\gamma>\alpha_{p}-\alpha_{w}-\left[\tilde{r}-r_{f}\right]$ or $\tilde{r}>\alpha_{p}+\gamma$. Indeed, if the combination of expected growth in output price and technological change was higher than the required rate of return, it would always be preferable to wait, without investing. Furthermore, as a profit function, $v(P, Z)$ is convex and increasing in $P$; it is also negative at $P=0$. As a result, the smooth pasting condition (A4) can be satisfied only if $c P^{b}$ is at least as convex as $v$.
} 
$e^{-\left[\alpha_{w}+\gamma\right] s} V_{p}(\partial p / \partial P)$ with $P=p / w_{M}$; substituting $V_{p}=a(T, \delta) Q$ and $w_{M}=e^{\alpha_{w} s}$ yields

$$
v_{P}(P, Z)=e^{-\gamma s} a(T, \delta) Q
$$

Substituting for $\beta$ and $v_{P}$ in (10) gives $\left(v\left(P^{*}, Z\right) / P^{*^{b}}\right) b P^{*^{b-1}}=e^{-\gamma s} a(T, \delta) Q$ which, using (4) and (5), reduces to

$$
\frac{b-1}{b} P^{*}=\frac{a(T, \rho) \sum_{i} W_{i} L_{i}+W_{K} K}{a(T, \delta) Q}
$$

This expression will be the basis of our econometric model. It deserves some comments. Since they solve problem (3), $Q$, the $L_{i}$ 's, and $K$ may be treated as a supply function and conditional factor demands respectively, while $T$ is the endogenous extraction period $R / Q$, reflecting the constraint imposed by the finiteness of reserves. As such, they are functions of $(P, Z)$ so that the right-hand side of $(12)$ may be written as

$U\left(Q^{*}(P, Z, s), Z, s\right) \equiv \frac{a\left(\frac{R}{Q^{*}(P, Z, s)}, \rho\right) \sum_{i} W_{i} L_{i}\left(Q^{*}(P, Z, s), Z, s\right)+W_{K} K\left(Q^{*}(P, Z, s), Z, s\right)}{a\left(\frac{R}{Q^{*}(P, Z, s)}, \delta\right) Q^{*}(P, Z, s)}$

The numerator gives total cumulative costs capitalized at $s$. By the definition of $a(T, \delta)$, the denominator is $\int_{0}^{T} e^{-\delta t} Q^{*} d t$, an output aggregator giving more weight to earlier production. Consequently, $U\left(Q^{*}(P, Z, s), Z, s\right)$ is a unit-cost function evaluated at the optimal level of $Q^{*}$. Thus (12) expresses the relationship between price and average total cost at the price $P^{*}$ which triggers the investment:

$$
P^{*}=B U\left(Q^{*}, Z, s\right)
$$

where $B \equiv b /(b-1)$ is the option premium multiple $(1<B<\infty)$, the price-cost ratio at which it becomes desirable to exercise the investment option. Finally, the assumption of a neutral form of technological change has led to a system of two equations (9) and 
(10) which define $\beta$ and $P^{*}$ implicitly as functions of $Z$ only; consequently, the right-hand side of (14) must also be independent of $s$. This requires

$$
\frac{\partial U}{\partial Q^{*}} \frac{\partial Q^{*}}{\partial s}=-\frac{\partial U}{\partial s}
$$

\section{THE EMPIRICAL ESTIMATION}

\subsection{Data organization and description}

The econometric model (17)-(18), described further below, consists of two simultaneous equations: one for capacity based on (6); one for the trigger price derived from (14). The data set is made of individual observations on Canadian copper mines. The sample covers the period 1954-1980, a period of major investment activity in that sector. Some of the investment decisions were decisions to wait; those did not result in the apparition of any new productive capacity. Others were decisions to go ahead with a project; those were followed by the introduction of productive capacity $c$ years after the decision. Our data set involves 60 such go-ahead decisions with actual start-up dates spread between 1960 and 1980. A few other investments involving copper extraction took place after 1980 but were not included in the sample because their major purpose was the mining of zinc.

The lag $c$ between the date $s$ at which the capacity is irreversibly chosen and the actual start-up date recorded in our data source was set at two years on the basis of heuristic information on mining projects. We also experimented with lags of zero, one, or two years, but the brief description which follows, and the more detailed one given in the appendix, correspond to $c=2$.

A total of 38 different firms, some of which were observed more than once, made the 60 capacity investments: 20 in British Columbia, 9 in Ontario, 8 in Québec, and 1 in the Yukon territory. To qualify, an investment has to correspond to the creation of a 
new operation, or to any capacity increase exceeding 20 percent of existing capacity. ${ }^{6}$

An observation is a vector of variables corresponding to the occurrence of a capacity investment, or to the failure of any investment to occur. The data set is an unbalanced panel where the dependent variables $P^{*}$ and $Q^{*}$ appear only once for each investment. It is organized as a succession of short time series whose dates may overlap. Each series corresponds to the 'history' of a particular investment. The last observation in each series corresponds to the actual investment, and the preceding observations correspond to a 'waiting period' over which the firm was - this is the hypothesis to be tested holding on to the option to invest.

\subsection{The output price process and the option premium}

The process corresponding to (1) for the relative price is $d P=\alpha P d t+\sigma P d z$. The random walk hypothesis is known to be rejected in favor of mean reversion when it is tested over the (century) long period for copper prices. Our point of view is different, as we are interested in durations relevant for capacity investment decisions (11 year on average) and as the decisions under investigation were all made in the post-war area and before 1980, a period that witnessed the energy shocks and over which a lot of casual evidence suggests that many experts and practitioners believed commodity price behavior could be governed by scarcity considerations à la Hotelling rather than longrun attraction toward some steady production cost. Dickey-Fuller tests may not be very powerful over medium range periods; the fact remains that they do not allow the rejection of the random walk hypothesis in the current instance. ${ }^{7}$

\footnotetext{
${ }^{6}$ In Harchaoui and Lasserre (1995) it was found that the capacity chosen was not affected by whether it was a creation, or an expansion.

${ }^{7}$ Consider the model

$$
\Delta P(t)=\eta_{0}+\eta_{t} t+\left[\eta_{P}-1\right] P_{t-1}+\sum_{j=1}^{4} \eta_{j} \Delta P_{t-j}+\zeta(t)
$$

where $\Delta P(t)=P(t)-P(t-1)$. Testing the random walk hypothesis involves the joint test that $\eta_{t}=\eta_{P}-1=\eta_{j}=0$. In order to verify whether this is an acceptable assumption from the point of view of a firm considering an investment at $s \in[1954-1980]$, we carried out the test for each of the 27 sub-periods $[s-14, s], s \in[1954-1980]$ and also over the period [1941 - 1980]. There is no period
} 
Nonetheless, since our model, as most of the underlying theoretical literature, relies on the assumption that the price follows a geometric Brownian motion, it is legitimate to wonder about the sensitivity of our results to that assumption. Simulations by Wey (1993) for oil reserves indicate that the option premium and the decision rule are not necessarily very different under mean reversion and under geometric random walk; roughly the difference depends on whether the mean value toward which reversion takes place is or is not very different from the cost of the project. Thus sensitivity is an empirical question. A similar issue is raised by our assumption that the price process has fixed coefficients: we investigate firms considering investments at $t \in[1954-1980]$ under the fixed-coefficient geometric random walk hypothesis; in order the estimates of $\alpha$ and $\sigma$ to reflect the information available at $t$ about the behavior of the relative price, we use different estimates $\alpha(t)$ and $\sigma(t)$ for each decision year. Thus the empirical experiment is one in which agents respond to changes in $\alpha$ or $\sigma$ as if they were completely unexpected, permanent, and never to be repeated; if changes were temporary, firms might respond less aggressively to price changes, much the same as they might do under a mean-reverting process. ${ }^{8}$

We cannot address these questions from within our econometric model because the theoretical model does not yield any analytical solution for the alternative price processes involved. Instead, we use numerical results from a stochastic dynamic programming model, to produce figures for comparison with the results obtained econometrically. These comparisons are discussed in Section 5; the results show little sensitivity to the assumed behavior of copper price.

To estimate the constant-coefficient geometric Brownian process, we use Slade's (1988) discrete approximation,

$$
\Delta P(\tau)=\alpha(t) P(\tau)+\xi(\tau)
$$

over which the geometric random walk is rejected.

${ }^{8}$ This interpretation was suggested by an anymous referee. 
where $\xi(\tau)$ is an heteroscedastic error term such that $\xi(\tau)=\sigma(t) P(\tau) \epsilon$. We estimate (16) over each of the 26 fourteen year periods preceding a capacity investment decision (whether a decision to wait or a decision to go ahead). The choice of a fourteen year estimation period is justified by the fact that the first investment decision that our data set allows us to consider occurs in 1954, while our price series starts in 1940 . We use the same period for later decisions for consistency. The estimated values of $\alpha(t)$ and $\sigma(t)$ respectively lay between $.5 \%$ and $5.3 \%$, and between $10.4 \%$ and $17.2 \%$.

The option premium coefficient is computed for each observation as $B(t)=b(t) /(b(t)-1)$ where $b(t)$ is given by $(8)$. Besides the price process parameters and the risk free and risk-adjusted interest rates, $b(t)$ depends on $\gamma$ the rate of technological progress. Although $\gamma$ is not observable, there is ample evidence of a significant regress, even when reserves and grade are controlled for. In particular, Stollery (1985) estimated the rate of total factor productivity growth for Canadian copper mines at $-1.40 \%$ over the 1957-65 period, $-3 \%$ over $1966-79$, and $-3.6 \%$ over $1971-79$. We experienced with alternative constant values of $\gamma$ between $-1 \%$ and $-7 \%$, generating the corresponding time series for $B$ in each case. The likelihood function of the trigger price equation culminates when we use the $B$ series corresponding to $\gamma=-6 \%$, retained for that reason in the rest of the paper. However models obtained with alternative $B$ series are not significantly different according to $J$ tests and yield similar economic results.

\subsection{Econometric model and estimation procedure}

Define $\ln Z=\left(\ln W_{l}, \ln W_{E}, \ln W_{K}, \ln \alpha, \ln \rho, \ln R, X, \ln G\right){ }^{9} x=(1, \ln B, \ln Z, s) ; y=$ $(1, \ln Z, s)$. The theoretical model implies that the vector $\ln Z$ is common to the capacity and the trigger price equations. We have substituted $\ln \alpha$ for the variable $\ln \delta$ implied by the theoretical model because $\delta$ and $\rho$ differ only by $\alpha$.

Suppose the profit function $V$ that generates the supply function is affected by a multiplicative error due to decision inaccuracy, uncertainty about demand, etc.. As an

\footnotetext{
${ }^{9}$ As a dummy variable, $X$ is left untransformed.
} 
implication of Hotelling's lemma, this error affects (6) multiplicatively; if we further assume that the supply function is loglinear, the latter may be represented by

$$
\begin{aligned}
\ln Q^{*} & =b_{0}+b_{P} \ln P+b_{Z} \ln Z^{\prime}+b_{s} s+\nu \\
& =b y^{\prime}+b_{P} \ln P+\nu
\end{aligned}
$$

where $b$ and $b_{Z}$ are row vectors of parameters, $b_{0}, b_{P}$, and $b_{s}$ are individual parameters, and $\nu$ is the logarithm of the profit function error term, which may be assumed to be zero on average. $P$ is the market price, not the trigger price, although both coincide at the dates when the investments are undertaken.

Assume that $\ln U$ is linear in $\ln Q^{*}$ and $\ln Z$. Then (14) may be written as

$$
\begin{aligned}
\ln P^{*} & =a_{0}+a_{B} \ln B+a_{Q} \ln Q^{*}+a_{Z} \ln Z^{\prime}+a_{s} s+\epsilon \\
& =a x^{\prime}+a_{Q} \ln Q^{*}+\epsilon
\end{aligned}
$$

where $\epsilon$ is an error term to be discussed momentarily and the $a$ 's are scalar or vector parameters. If (14) is true, then $a_{B}=1$. This is the basis of our test of option theory: the option premium should affect the trigger price positively; in a logarithmic model, the coefficient of proportionality is precisely 1 . The error term $\epsilon$ does not originate from the error term discussed above affecting the profit function (hence $v$ ) multiplicatively. This may be verified by considering the value matching condition (10) used in the derivation of (14): since $\beta$ in (10) is given by (9), that error on $v$ is on sides of (10) and washes out. Besides inaccuracy in the timing decision, a major source for the error in (18) is measurement error on both the dependent and the explanatory variables: rather than being measured on decision day, the variables are yearly averages. On average this error can be expected to be zero.

Error terms may be heteroscedastic if they contain firm specific components, due to differences in size or to the fact that some investments are capacity expansions while 
others are creations. We have investigated this by introducing dummy variables based on creation versus expansion, the number of times a firm is sampled, geographical location, or the type of exploitation (open pit versus underground); the latter variable $X$ is the only one with a marginally significant impact. White tests were also applied to the residuals of both equations and conclude to the rejection of heteroscedasticity.

Error terms may also be affected by various measurement errors and by misspecification. First, the loglinear form may be a misspecification. However, models that include second-order terms (second-order, rather than first-order, approximations of the true models) do not dominate the linear ones in J-tests, nor does this alternative specification affect our major conclusion (the coefficient of $\ln B$ is practically unchanged). Second, our failure to model shut-down and expansion options affects the theoretical evaluation of the investment option and may affect the trigger price. If these options matter, $B$ is computed from the wrong theoretical formula, a problem compounded by our use of estimated price-process parameters. However, the important explanatory variables would be the same so that no systematic effect on the error terms is likely to result. The theoretical prediction that $a_{B}=1$ might be affected, although, to the extent that the alternative theoretical model implies that the trigger price exceeds average cost by some option premium, the sign of $a_{B}$ should remain positive. In such a context, a rejection of the null hypothesis $a_{B}=1$ should be taken with caution, both because the null hypothesis might be off-mark, and because, as shown by Pagan (1984), the power of the tests may be lower than in conventional situations.

On the basis of the above discussion we may assume that the error terms in (17) and (18) follow uniform distributions with zero means; we further assume that the distributions are normal, with standard errors of $\sigma_{\nu}$ and $\sigma_{\varepsilon}$ respectively, and covariance $\sigma_{\varepsilon \nu}$. These full-sample distributions may be affected by censoring. In the full sample 268 observation data set, $P^{*}$ and $Q^{*}$ are observed when $P^{*}$ overtakes $P$ for the first time; otherwise neither $P^{*}$ nor $Q^{*}$ are observed, although $P$ is. Then the distribution of $\epsilon$ corresponding to the sub-sample where $P^{*}$ is known has not zero mean. It may be 
shown that, for any observation $i$ where $P^{*}$ is known

$$
E\left(\epsilon_{i} \mid \ln P_{i} \geq \ln P_{i}^{*}\right)=-\sigma_{\varepsilon} \frac{\phi\left(\Delta_{P_{i}}\right)}{\Phi\left(\Delta_{P_{i}}\right)}
$$

where $\Delta_{P_{i}}=\left(\ln P_{i}-a x_{i}^{\prime}-a_{Q} \ln Q_{i}^{*}\right) / \sigma_{e}$ while $\phi$ and $\Phi$ are the density and cumulative functions of the standard normal distribution.

In contrast, the distribution of $\nu$ in the sub-sample is less likely to be biased in any direction relative to its full sample distribution. This is because the truncation does not depend on $Q^{*}$ exceeding some particular level but on $\ln P$ exceeding $\ln P^{*}$ so that a truncation bias will arise only if there is a significant covariance between the error arising in the censored sample on the price equation, and $\nu$. Precisely, it may be shown that (see Maddala, 1996, p.224), for any observation $i$ where $Q^{*}$ (or $P^{*}$ ) is known

$$
E\left(\nu_{i} \mid \ln P_{i} \geq \ln P_{i}^{*}\right)=-\frac{\sigma_{\nu u}}{\sigma_{u}} \frac{\phi\left(\Delta_{Q_{i}}\right)}{\Phi\left(\Delta_{Q_{i}}\right)}
$$

where $\Delta_{Q_{i}}=\left(\left[1-a_{Q} b_{P}\right] \ln P_{i}-a x_{i}^{\prime}-a_{Q} b y_{i}^{\prime}\right) / \sigma_{u}$; and the stochastic variable $u \equiv \epsilon+a_{Q} \nu$ is normally distributed with zero expected value, variance $\sigma_{u}^{2}=\sigma_{\varepsilon}^{2}+a_{Q}^{2} \sigma_{\nu}^{2}+2 a_{Q} \sigma_{\varepsilon \nu}$ and covariance (with $\nu) \sigma_{\nu u}=E\left(\left[\epsilon+a_{Q} \nu\right] \nu\right)=\sigma_{\varepsilon \nu}+a_{Q} \sigma_{\nu}^{2}$.

Equations (18) and (17) represent a simultaneous-equation model with censoring. Identification is possible even if the residuals in the two equations are correlated because the price equation includes the variable $\ln B$, not present in the quantity equation (Maddala, 1996, ch. 8). ${ }^{10}$ Given (19) and (20), the structural form may be estimated by Heckman's two-stage method. Since only (18) includes an endogenous variable $\ln Q^{*}$ on its right-hand side, the simultaneity problem is dealt with by first estimating (17) and then using the predicted value of $Q^{*}$ in (18).

Let $I=1$ if $Q^{*}$ (and $P^{*}$ ) is observed and $I=0$ otherwise. Expression (20) implies

\footnotetext{
${ }^{10}$ As pointed out by a referee, although some of the variables from which $B$ is computed are also in the quantity equation, the volatility $\sigma$ appears only in $B$. In practice $\ln \rho$ was also eliminated from the price equation.
} 
that the following augmented equation may be used to estimate the capacity model on the sub-sample corresponding to $I=1$ (see Maddala, 1996, esp. ch. 8, for details)

$$
\ln Q^{*}=b y^{\prime}+b_{P} \ln P+b_{M} \frac{\phi\left(\Delta_{Q}\right)}{\Phi\left(\Delta_{Q}\right)}+\nu_{2}
$$

where $\nu_{2}$ has a standard normal distribution. The coefficient $b_{M}$ provides an estimate of

$-\frac{\sigma_{\nu u}}{\sigma_{u}}$. In order to compute the inverse Mills ratio $\phi\left(\Delta_{Q}\right) / \Phi\left(\Delta_{Q}\right)$, the two-stage method requires estimating $\Delta_{Q}$ by running a probit of $I$ on the variables in $\Delta_{Q}$ : $\ln P$ and the variables in either $y$ or $x$. The estimated value of $\Delta_{Q}, \hat{\Delta}_{Q}$ is then used to approximate the variable $\phi\left(\Delta_{Q}\right) / \Phi\left(\Delta_{Q}\right)$.

When this two-stage procedure was implemented, the $t$ statistic associated with $b_{M}$ was .09 (Table 1, column 3), implying that censoring is a negligible issue when estimating (17) from the $I>0$ sub-sample. Consequently we reestimated the equation without including Mills ratio among the explanatory variables (Column 4). The predicted value $\ln \hat{Q}^{*}$, of $\ln Q^{*}$ was then used as explanatory variable in (18).

\section{PLEASE INSERT TABLE 1 AROUND HERE}

Equation (18) may be estimated by using the two-stage method again. The secondstage, augmented, model (estimated on the sub-sample corresponding to $I>0$ ) is:

$$
\ln P^{*}=a x^{\prime}+a_{Q} \ln \hat{Q}^{*}+a_{M} \frac{\phi\left(\hat{\Delta}_{P}\right)}{\Phi\left(\hat{\Delta}_{P}\right)}+\epsilon_{2}
$$

where $\epsilon_{2}$ is a normally distributed residual whose expected value is zero. Since $\Delta_{P_{i}}=$ $\left(\ln P_{i}-a x_{i}^{\prime}-a_{Q} \ln Q_{i}^{*}\right) / \sigma_{e}$, where $\ln P$ has a coefficient of unity, we used the likelihood function $\prod_{I=\mathbf{0}}\left[1-\Phi\left(\ln P_{i}-a x_{i}^{\prime}-a_{Q} \ln Q_{i}^{*}\right)\right] \prod_{I=1} \Phi\left(\ln P_{i}-a x_{i}^{\prime}-a_{Q} \ln Q_{i}^{*}\right)$. Columns 5 and 7 report the first stage probit estimations for $\gamma=-3 \%$ and $-6 \%$ respectively. Columns 6 and 8 give the corresponding second-stage results; the reported $t$ statistics for these two price equations are obtained by following Maddala's procedure (pp. 25356 ), using his formula $(A 4)$. Finally, in Column 9, we present the results of estimating a 
reduced form obtained by substituting (17) into (18). This reduced form does not permit the identification of $a_{B}$ but we use it to test restriction (15), implied by the assumption of neutral technological change. The corresponding cross-equation restriction $a_{Q} b_{s}-a_{s}=0$ is satisfied if the coefficient of $s$ is zero in Column 9, which the $t$ statistic of -.43 allows to accept.

\section{RESUlT DISCUSSION AND CONCLUSION}

We may now focus on column 4 , giving the results of estimating the capacity equation (17), and column 8, giving the results for the trigger price equation (22). With $R^{2}$ 's ranging from .95 to .99 , both equations have a good explanatory power. If the option value of remaining flexible is important, the coefficient of $\ln B$ should be significant in

column 8; furthermore it should not be significantly different from 1 . Since $a_{B}=1.64(t$ statistics of 3.06 against the maintained hypothesis $a_{B}=0$; $t$ statistics of 1.19 against the maintained hypothesis $a_{B}=1$ ), the model passes these two tests. The paper also rejects a 'naive NPV rule', to borrow the words of Abel et al. (1996), whereby the expected present value of revenues minus costs should be zero at the time of investment. When $B$ is computed using alternative values of $\gamma$ ranging from $-1 \%$ to $-7 \%$, the results are similar (see Column 6 for $\gamma=-3 \%$ ).

Given the strong assumptions underlying the model one might be concerned about the robustness of the reported estimates, especially the significance and magnitude of the impact of $B$, our measure of the option premium. Despite the various tests and checks described earlier, a major potential source of error on $B$ remains the assumption that the price follows a geometric Brownian motion. This assumption cannot be tested by econometric methods within the general methodology of the paper because, for most alternative price processes, including the prominent candidate, a mean-reverting process, the theoretical model does not yield any explicit solution for the trigger price. In order to assess the error possibly involved, we provide some numerical simulations of the trigger price and the corresponding price-cost margin when the price follows a mean-reverting 
process. They are presented and compared with their (geometric Brownian motion) counterparts in Graphs 1 and $2 .^{11}$

Although no hypothesis test is readily available for such a procedure, we find that there is a remarkable similarity between the implied option premia under both alternative assumptions. Graph 1 shows that the trigger price fluctuates less widely under mean reversion, probably because price changes are perceived of a temporary nature and require less aggressive a reaction. Such a behavior might also be expected if firms considered changes in the parameters of the price process not to be of a permanent nature.

Graph 2 presents the option premium multiples, computed as the ratio 'predicted trigger price over predicted unit cost' for the geometric Brownian motion (Table 1, col. 8), or obtained numerically for the mean-reverting process; the striking similarity between the two curves is an indication that the qualitative implications of our results are not overly sensitive to the strong assumptions made.

\section{PLEASE INSERT GRAPHS 1 AND 2 AROUND HERE}

The validation of the real-options model is welcome, as alternative theories have a relatively poor record of explaining observed investment behavior. In particular, as documented by Chirinko (1993), alternative models imply that prices (especially output price and the user cost of capital) should explain a higher proportion of variations in investment than is actually found in empirical work. In contrast the option model, while not ruling out such an influence, implies that the influence of prices may also be manifest in the timing of investments. Similarly, empirical neoclassical supply models,

\footnotetext{
${ }^{11}$ For each of the 60 capacity investments in our data set, we solved a stochastic dynamic programming investment decision problem based on a binomial approximation of a mean-reverting price process. Since we could not rely on econometric inference to determine project values, we used hypothetical values. More precisely, we addressed the following question. Let $\hat{v}(P)$ be the predicted project value inferred from the econometric model under the assumption that the price follows a geometric Brownian motion. Suppose that a firm holds a project worth $\hat{v}(P)$ where $P$ follows a mean-reverting process (estimated from our price data) rather than a geometric Brownian one; what is the critical price $P^{M}$ at which it would invest into the project and to what extent would $P^{M}$ differ from the critical price under Brownian motion?
} 
especially in resource sectors, often find that output price explains supply poorly; indeed this must be expected in models such as the option model where capacity is adjusted only occasionally.

How much does the option premium affect copper mine investment? For a rough answer, one may compute how many years it takes for the price to move by an order of magnitude corresponding to the trigger premium: on average, it takes 3.5 years for the price to move up or down by the average size of the trigger premium, which represents $15 \%$ of the trigger price on average. Of course the impact of changes in $B$ is smaller; it takes on average 1.5 years for the price to move up or down by the average yearly change in the premium.

At a more sophisticated level of analysis, one has to note that the same factors that drive the option premium may also affect the characteristics of the project. For example, while Graph 2 shows a striking correlation between $B$ and the price drift $\alpha$, the correlation between the trigger price and $\alpha$ is much less pronounced. The reason is that a rise in $\alpha$ increases $B$ but also reduces the unit cost $U$ on which the premium is applied: the rise in $\alpha$ implies that future output fetches a higher price; this amounts to a rise in cumulative output, hence a drop in unit cost. Consequently the effect on the trigger price is dampened, as one can see by comparing the sharp increases in both $\alpha$ and the premium noticeable on Graph 2 at observation \#12, with the corresponding change in the trigger price on Graph 1. Thus taking project endogeneity into account in real options models may be crucial.

The strong correlation between $\alpha$ and $B$ evident on Graph 2 would appear to contradict the belief often derived from the finance literature that volatility, not expected price change, matters. In fact, from the three variables involved in the expected return identity $\tilde{r} \equiv \mu+\alpha$, where $\mu$ is the dividend or the convenience yield, it is customary in the finance literature to eliminate $\alpha$ by expressing it in terms of the other two; this does not mean that $\alpha$ does not matter but that its impact is accounted for by $\tilde{r}$ and $\mu$. In our real-options context, the convenience yield is not measurable so that it is more practical to focus on $\alpha$, as we have done (see Appendix). Intuitively, the higher $\alpha$, the 
likelier it is that the price will be high in the future; the cost of waiting relative to the value of future prospects being lower, waiting becomes more attractive which calls for a higher trigger price. In fact, neither the volatility of the Brownian process, nor the parameters of the mean-reversal process (average price, reversal parameter, volatility), have such a striking impact on the option premium as the drift of the Brownian process. This does not mean that volatility does not matter; however, as Graph 2 indicates, it has not experienced much variation.

Table 2 allows more precision in the analysis. Since the estimated elasticity of $P^{*}$ with respect to $B$ is 1.64 , the implied elasticity of $P^{*}$ with respect to $\sigma$ may be obtained from the definition of $B$ using (8): ${ }^{12}$ at the mean value of the relevant variables that elasticity is 1.87. This confirms that uncertainty has a major dampening effect on investment; however, in the current instance, the relative stability of $\sigma$ implies that it is not responsible for much of the variation in the trigger price. Similar elasticity calculations (at mean values of all variables) with respect to the variables that determine $B$ indicate that the elasticity of $P^{*}$ with respect to $\alpha$ (resp. $\gamma$ ) is $1.01(.68)$.

Finally, the elasticities with respect to the risk adjusted interest rate and the risk free interest rate, at -2.04 and .77 respectively, cast the remark of Chirinko (1993) that the user cost has little practical relevance in empirical models of investment in a new light. It appears that much of the effect of interest rates on real investment may occur through the option premium channel rather than via the user cost. An increase in the cost of borrowing $\tilde{r}$ reduces the expected value of future incomes; hence it also reduces the value of waiting while not affecting the opportunity cost of waiting which reflects

\footnotetext{
${ }^{12}$ The elasticities of $P^{*}$ with respect to the variables that determine $B$ are obtained by the following formula, applied here to the case of $\sigma$ :$$
\epsilon_{P, \sigma}\left(\sigma, \alpha, \tilde{r}, r_{f} ; \gamma\right)=\frac{\partial \ln P^{*}}{\partial \ln B} \frac{\partial B(b)}{\partial b} \frac{\partial b\left(\sigma, \alpha, \tilde{r}, r_{f} ; \gamma\right)}{\partial \sigma} \frac{\sigma}{B}
$$

with $B(b)=b\left(\sigma, \alpha, \tilde{r}, r_{f} ; \gamma\right) /\left(b\left(\sigma, \alpha, \tilde{r}, r_{f} ; \gamma\right)-1\right)$ where $b$ is given by $(8)$. In our model, more uncertainty increases the value of the call option to undertake the project, which reduces the incentive to invest, implying a higher trigger price. This contrasts sharply with models such as Abel (1985) where an increase in uncertainty implies more opportunities to adjust to fluctuations in the future, an incentive to hold more capital. In models such as Abel et al. (1996), the firm holds both a put option (to shrink) and a call option (to expand), so that uncertainty has an ambiguous effect.
} 
current foregone income. Consequently, an increase in $\tilde{r}$ makes immediate investment more attractive, reducing the trigger price. This effect in favor of immediate investment runs counter to the negative cost of capital effect on which the neoclassical investment model has traditionally focused, and may explain the low impact noted by Chirinko. An increase in both $\tilde{r}$ and $r_{f}$ that would preserve the risk premium would reduce $P^{*}$.

The discussion sofar has been focused mostly on the option pricing model. An important feature of our model, often ignored in the theoretical option-value literature where projects have been treated typically as exogenous, is the jointness of timing, and project size, decisions. With an elasticity of $P^{*}$ with respect to $Q^{*}$ of $.89(t=3.96)$, the dimension of the project is an important and highly significant determinant of the trigger price. This effect is not related to the option premium but reflects the rise in unit cost associated with high scale. Because our definition of unit cost (13) involves the capitalization of costs and output over the life of the mine, this cost rise reflects the shortening of the extraction period, requiring faster sunk-cost amortization, implied by larger scale.

Turning to the capacity choice equation (Column 4), we note that capacity is significantly positively related to output price, and that the corresponding elasticity of 1.18 $(t=1.93)$ is fairly high. In a neoclassical supply model the estimated elasticity would probably have been lower, perhaps not significant, because observations where capacity was not adjusted would have been treated the same way as instances where it was increased. Here the elasticity reflects the ex ante influence of price on capacity. This result does not contradict the finding that output price has little effect on supply in general; but it does mean that output price plays a significant role occasionally, when capacity decisions are made. Nonetheless geological considerations play the key role in the choice of scale: higher reserves call for a higher production rate (elasticity: $.63 ; t=24.14$ ); a high ore grade $G$ is associated with lower scale, in accordance with the observation that high-grade deposits are often small and of odd shapes.

Why does the price drift $\alpha$ have a negative impact? From the point of view of discounted future revenues, a high $\alpha$ is equivalent to a low discount rate. As explained 
in the resource literature, the discount rate has an ambiguous effect on the rate of extraction of an exhaustible resource when capital is used as an input: on one hand, a low discount rate implies a low user cost of capital; on the other hand, the same low discount rate implies a high resource rent, calling for slow extraction. In the specification adopted here, $W_{K}$ picks up the input price effect, while $\alpha$ picks up the resource rent effect: when copper prices are expected to rise, there is a gain involved in economizing on the exhaustible resource by adopting a slow extraction path.

The option value model of real, irreversible, investment appears to explain capacity decisions and timing decisions in a satisfactory way, both from a statistical and from an economic point of view. This allows us to be hopeful that option theory, as applied to real investment, may become a useful tool of empirical investigation. Until now, it has been much used in simulations but little as a basis for statistical inference. Of course, many gaps remain to be filled. Many features that have been studied in the theoretical literature were left out of our model. In particular, we did not consider the possibility of further capacity expansions; we did not consider the duration of the investment process; we ignored, although on good empirical grounds, the option to shut down during the mine's life; we focused on output price as the single source of uncertainty, using a procedure which remains conditional on the validity of the Brownian-motion assumption. These are serious restrictions which beg to be eliminated in further work, if the theory is to be successfully used in wider a range of applications.

Tarek M. Harchaoui Microeconomic Analysis Division Statistics Canada.

Pierre Lasserre Université du Québec à Montréal, CIRANO (Montréal), and GREQAM (Université d'Aix-Marseille II).

\section{References}

Abel, A. B. (1985) "A Stochastic Model of Investment, Marginal q and the Market Value of the Firm" International Economic Review 26(2), 305-22.

Abel, A. B. A. K. Dixit, J. C. Eberly, and R. S. Pindyck (1996) "Options, the Value of Capital, and Investment" Quarterly Journal of Economics 111(august), 753-77. 
Arrow, K. J. and A. C. Fisher (1974) "Environmental Preservation, Uncertainty, and Irreversibility" Quarterly Journal of Economics 88, 312-19.

Bell, G. K. and J. M. Campa (1997) "Irreversible Investments and Volatile Markets: A Study of the Chemical Processing Industry" Review of Economics and Statistics 79(1), 79-87.

Bernanke, B. (1983) "Irreversibility, Uncertainty, and Cyclical Investment" Quarterly Journal of Economics 98, 85-106.

Brennan, M. J. and E. S. Schwartz (1985) "Evaluating Natural Resource Investments" Journal of Business 58, 135-57.

Caballero, R. J. and R. S. (1996) "Uncertainty, Investment, and Industry Evolution" International Economic Review 37(3), 641-62.

Chirinko, R. S (1993) "Business Fixed Investment Spending: Modeling Strategies, Empirical Results, and Policy Implications" Journal of Economic Literature 31, 1875-1911.

Conrad, R. F. and R. B. Hool (1980) Taxation of Mineral Resources Lexington: Lexington Books.

Dixit, A. and R. S. Pindyck (1994) Investment under Uncertainty Princeton: Princeton University Press.

Harchaoui, T. M. and P. Lasserre (1995) "Testing the Impact of Taxation on Capacity Choice: A 'Putty clay' Approach" Journal of Public Economics 56, 377-411.

Henry, C. (1974) "Investment Decisions under Uncertainty: the Irreversibility Effect" American Economic Review 64, 1006-12.

Hurn, A. S. and R. E. Wright (1994) "Geology or Economics? Testing Models of Irreversible Investment Using North Sea Oil Data" Economic Journal 104(423), 363-71.

Ingersoll, J. E. and S. A. Ross (1992) "Waiting to Invest: Investment and Uncertainty" Journal of Business 65, 1-29.

Lasserre, P. (1985) "Capacity Choice by Mines" Canadian Journal of Economics 18(4), 
$831-42$.

Leahy, J. V. and T. M. Whited (1996) "The Effect of Uncertainty on Investment: Some Stylized Facts" Journal of Money, Credit, and Banking 28(1), 64-83.

Mackie-Mason, J. K. (1990) "Nonlinear Taxation of Risky Assets and Investment, with Application to Mining" Journal of Public Economics 42, 301-27.

Maddala, G. S. (1996) Limited Dependent and Qualitative Variables in Econometrics Cambridge University Press: Cambridge, England.

Majd, S. and R. S. Pindyck (1987) "Time to Build, Option Value, and Investment Decisions" Journal of Financial Economics 18, 7-27.

McDonald, R. and D. Siegel (1985) "Investment and the Valuation of Firms When There is an Option to Shut Down" International Economic Review 26, 331-49.

Paddock, J. L., D. R. Siegel, and J. L. Smith (1988) "Option Valuation of Claims on Real Assets: The Case of Offshore Petroleum Leases" Quarterly Journal of Economics 103, $479-508$.

Pagan, A. (1984) "Econometric Issues in the Analysis of Regressions with Generated Regressors" International Economic Review 25(1), 221-47

Pindyck, R. S. (1988) "Irreversible Investment, Capacity Choice, and the Value of the Firm" American Economic Review 78, 969-85.

Pindyck, R. S. (1991) "Irreversibility, Uncertainty, and Investment" Journal of Economic Literature 60, 1110-48.

Pindyck, R. S. and A. Solimano (1993) "Economic Instability and Aggregate Investment" NBER Macroeconomics Annual 8.

Quigg, L. (1993) "Empirical Testing of Real Option-Pricing Models" Journal of Finance 48(2), 621-40.

Slade, M.E. (1988) "Grade Selection Under Uncertainty: Least Cost Last and other Anomalies" Journal of Environmental Economics and Management 15, 189-205. 
Slade, M. E. (1997) "Managing Projects Flexibly: An Application of Real-Option Theory" mimeo, Department of Economics, University of British Columbia, Vancouver.

Stollery, K.R. (1985) "The Effect of Changing Ore Grade on the Rates of Change in the Productivity of Canadian Mining Industries" Applied Economics 17, 543-58.

Tourinho, O. A. (1979) "The Valuation of Reserves of Natural Resources: An Option Pricing Approach" Unpublished Ph. D. dissertation, University of California.

Wey, L. (1993) "Effects of Mean-Reversion on the Valuation of Offshore Oil Reserves and Optimal Investment Rules" Unpublished undergraduate thesis, MIT, May. 


\section{Appendix 1: Evaluation of the investment option}

The option is worth $\Pi(P, Z, t)=E_{t}\left\{v(P, Z) e^{\left[\alpha_{w}+\gamma\right] s} e^{-r[s-t]}\right\}$. If, over an interval $[t-\varepsilon, t+\varepsilon], P$ and $Z$ do not change, then the probability that the option to invest will be exercised at $t^{\prime}+\tau$ is the same for any $t^{\prime}$ in that interval, and this is true for any $\tau \geq 0$. This implies that $\Pi_{t} d t$ may be obtained by differentiating $E_{t}\left\{v(P, Z) e^{\left[\alpha_{w}+\gamma\right] s} e^{-r[s-t]}\right\}$ totally while maintaining $d s=d t$ and $d Z=d P=0$. It follows that $\Pi_{t}=\left[\alpha_{w}+\gamma\right] \Pi$.

To evaluate $\Pi$, we construct a portfolio consisting of the option and a short position consisting of $n$ units of $x$, where $n$ is selected in such a way that the portfolio is riskless. By the CAPM, in order to accept holding one unit of $x$, the party entering the long side of the transaction will expect a return of $\tilde{r}=r_{f}+\left[\left(r_{m}-r_{f}\right) / \sigma_{m}\right] \rho_{x m} \sigma$, where $r_{m}$ is the expected market rate of return, $\sigma_{m}$ is the standard deviation of that return, $r_{f}$ is the risk-free rate of return, and $\rho_{x m}$ is the coefficient of correlation between the return on $x$ and the market return. This return must be produced by the combined price increase and convenience yield $\mu$, so that $\mu=\tilde{r}-\alpha$. . The convenience yield, amounts to a cost to the portfolio holder of $n \mu P d t$ per interval of time $d t$. Thus the portfolio, which is worth $\Pi-n x$, yields in total, over $d t, d \Pi-n d P-n \mu P d t$. Evaluating $d \Pi$ by Ito's lemma, and substituting for $d P$ and $d P^{2}$, this yield becomes

$$
\Pi_{P}[\alpha P d t+\sigma P d z]+\frac{1}{2} \Pi_{P P} \sigma^{2} P^{2} d t+\Pi_{t} d t-n[\alpha P d t+\sigma P d z]-n[\tilde{r}-\alpha] P d t
$$

This is riskless if $n=\Pi_{P}$. Non arbitrage requires the yield to equal the riskless return on the value of the portfolio: $\left\{\frac{1}{2} \sigma^{2} P^{2} \Pi_{P P}-[\tilde{r}-\alpha] P \Pi_{P}+\Pi_{t}\right\} d t=r_{f}\left[\Pi-P \Pi_{P}\right] d t$. 
Dividing by $d t$ and rearranging we obtain

$$
r_{f} \Pi=\left[\alpha-\left[\tilde{r}-r_{f}\right]\right] P \Pi_{P}+\frac{1}{2} \sigma^{2} P^{2} \Pi_{P P}+\Pi_{t}
$$

This is a partial differential equation. However, consider the corresponding pseudooption defined as

$$
\pi(P, Z)=\Pi(P, Z, t) e^{-\left[\alpha_{w}+\gamma\right] t}
$$

This pseudo-option is time autonomous because $\Pi_{t}=\left[\alpha_{w}+\gamma\right] \Pi$; also, $\pi_{P}=\Pi_{P} e^{-\left[\alpha_{w}+\gamma\right] t}$ and $\pi_{P P}=\Pi_{P P} e^{-\left[\alpha_{w}+\gamma\right] t}$. Substituting into $(A 1)$, and defining $\rho_{f} \equiv r_{f}-\alpha_{w}$, we obtain Equation (7). It may be verified that $\pi(P, Z)=\beta P^{b}$ solves (7) and satisfies the boundary conditions ( $\pi=0$ when the price is null; value matching; smooth pasting):

$$
\begin{aligned}
\pi(0, Z) & =0 \\
\pi\left(P^{*}, Z\right) & =v\left(P^{*}, Z\right) \\
\pi_{P}\left(P^{*}, Z\right) & =v_{P}\left(P^{*}, Z\right)
\end{aligned}
$$

The trigger price $P^{*}$ and the parameter $\beta$ are obtained from (A3) and (A4): (A3) implies (9): $\beta=v\left(P^{*}, Z\right) / P^{*^{b}}$ and, substtituting for $\pi_{P}$ in (A4) gives $(10)$ : $\beta b{P^{*-1}}^{b}=$ $v_{P}\left(P^{*}, Z\right)$. 


\section{Appendix 2: Data}

This Appendix lists the major capacity investments investigated in the paper, explains data organization, and describes variables and sources; sources are given as Roman numbers between brackets and listed at the end of the appendix.

\section{A Firm name, location, and investment dates [II]}

Copper Rand Mine, Québec, 1960, 1968, 1970; Craigmont Mines, British Columbia, 1961, 1962; Vauze Mines, Québec, 1961; Bethlehem Copper, British Columbia, 1962, 1964, 1966, 1967, 1971, 1976; Coast Copper Co. Ltd., British Columbia, 1962; Phoenix Copper. British Columbia, 1962, 1963, 1969; Solbec Mines, Québec, 1962; Sunro Mines, British Columbia, 1963; Kam Kotia Mines Ltd., Ontario, 1963, 1968; Manitouadge Mines, Ontario, 1963; Lake Dufault Mines, Québec, 1964; Copper Corp. Ltd., Ontario, 1965; Lorraine Mining Corp., Québec, 1965; Minoca Mines, British Columbia, 1965; Endako Mines, British Columbia, 1965, 1967, 1978; Kidd Creek Mines, Ontario, 1966, 1978; Westmin Resource Ltd., British Columbia, 1966, 1968; Kidd Copper Mines, Ontario, 1966; Granisle Mines, British Columbia, 1966, 1972; Whitehorse Copper Mines, Yukon, 1967; Prace Mining Corp., Ontario, 1967; Munro Copper, Ontario, 1967; Mines Gaspe, Québec, 1968, 1973; Madeleine Mines Ltd., Québec,1969; Cons. Churchill Copper Corp., British Columbia, 1970; Renzy Mines Ltd., Québec, 1970; Geco Mines, British Columbia, 1970; Brenda Mines, British Columbia, 1970; Island Copper Mines, British Columbia, 1971; Opemiska Mines, Québec, 1971; Lornex Mining Corp., British Columbia, 1972, 1974, 1979; Gilbraltar Mines, British Columbia, 1972; Similkameen Mining, British Columbia, 1972, 1975; Bell Copper Mines, British Columbia, 1972; Maybrun Mines Ltd., Ontario, 1973; Sturgeon Lake Mines, Ontario, 1975; Thierry Mines, Ontario, 1976; Afton Mines, British Columbia, 1978; Equity Silver Mining, British Columbia, 1980; Highmont Mines, British Columbia, 1980.

\section{B Description of the data set}

In 1960 the Copper Rand Mine started its new operation in Québec. Since we assume that $c=2$, the decision was taken in 1958, based on information (price and economic as well as geological data) available at that date. We hypothesize that, prior to 1958, the firm was observing new information as it became available and was actually holding on to the option to invest. If the theory is correct, the firm decided to wait during the years preceding 1958 , and decided to go ahead in 1958. This approach would not be valid if the ore deposit had just been discovered, so that 1958 would be the first opportunity for the firm to exercise its option. However, the data indicate only a few instances of minor corrections or validations of reserve figures made in the period immediately preceding an investment, allowing us to assume that the geological variables $(R, X, G)$ were known and had the same value $(R(s), X(s), G(s))$ during the 'waiting period' as at $s$.

According to the theory, the price of copper was too low for the investment of the Copper Rand Mine to take place during the 'waiting period' $\left(P<P^{*}\right)$ and it reached $P^{*}$ (plus or minus an error term) in 1958. Thus in 1958 we observe the trigger price and the capacity chosen $Q^{*}$ (as recorded at start-up date in 1960). The year $s=1958$ for the Copper Rand Mine corresponds to an observation where both $P^{*}$ and $Q^{*}$ are observed. During the waiting period neither $P^{*}$ nor $Q^{*}$ are observed. All other relevant variables are observed whether the firm is 'waiting' or 'going ahead'.

The 'waiting period' is set at four year, unless a firm made major capacity investments at intervals of less than four years, in which case we reduce the period in such a way that the time series for any two investments by the same firm do not overlap. Thus our data set starts with five observations associated with the Copper Rand Mine: 1954, 1955, 1956, and 1957 are observations that include all explanatory variables but for which the dependent variables $P^{*}$ and $Q^{*}$ are not available; 1958 includes the same explanatory variables, as well as $P^{*}$ and $Q^{*}$. The second investment that we consider was made by Craigmont Mines 
(British Columbia) in 1961. It generates another series of five observations that are stacked after the five observations corresponding to Copper Rand's 1960 investment: 1955, 1956, 1957, 1958, and 1959. Thus the first two series of five observations overlap by four years. Output and factor prices, as well as interest rates, are the same in both series for their common years; geological variables (reserves, grade, type of exploitation) differ between the two series because the mines are different, but stay at the same value during the five years of any series. Similarly the tax parameters used to adjust prices differ between the two series because the two mines are located in different provinces.

Stacking in such a way series of 5 observations for each of the 60 capacity investments would generate a data set of 300 observations. However, as mentioned, some mines invested more than once at intervals of less than five years. In such cases the 'waiting period' was reduced in such a way that the time periods corresponding to different investments by any one firm do not overlap. Thus the Copper Rand Mine expanded in 1968 and again in 1970. The 1968 expansion (final decision in 1966) generates five observations (1962-66) which do not overlap with the first five observations mentioned above (1954-58). However, if the 'waiting period' corresponding to the 1970 expansion was not reduced, the latter would generate a series (1964-68) that would overlap with the previous (1962-66) series; consequently we allow only two observations (1967-68) for the last Copper Rand Mine expansion. As a result of these adjustments, the data set includes 268 observations, 60 of which include the dependent variables $P^{*}$ and $Q^{*}$.

An observation always consists of, or make use of variables constructed from, the following variables (in alphabetical order, first Latin, then Greek):

$B(t)$ : option premium coefficient at year $t ; B(t)=b(t) /(b(t)-1)$ with $b(t)$ given by (8); (8) involves the time series variables $\alpha(t), \sigma(t), \tilde{r}(t), r_{f}(t), \rho_{f}(t)$, and the constant $\gamma$.

$G(i)$ : ore grade, in percentage, for investment $i$ (constant over the waiting period);

$P(t, i)$ : after-tax flow price of copper relative to materials at $t$ for project $i$ (the price may differ at any date between projects if the tax parameters differ);

$P^{*}(t, i)$ : exercise price at $t$ for project $i$ relative to the price of material; $P$ and $P^{*}$ coincide up to an error term when an investment occurs; otherwise $P^{*}$ is not observed;

$Q^{*}(t, i)$ : optimal capacity at $t$ for project $i\left(Q^{*}\right.$ is observed only when an investment occurs);

$r(t)$ : real discount rate for long-term projects at $t$; we set $r(t)=\tilde{r}(t)$;

$r_{f}(t)$ : risk-free real interest rate at $t$

$\tilde{r}(t)$ : risk-adjusted real rate of return at $t$;

$R(i)$ : mineral reserves for investment $i$ (constant over the waiting period);

$s(i)$ : year of the go ahead decision for project $i ; s=S-c ; c=2 ; S(i)$ : year of production start-up for project $i$;

$t$ : year of a major capacity investment decision (wait, or go ahead);

$W_{l}(t, i), W_{E}(t, i)$ : after-tax flow prices of labor and energy relative to materials at $t$ for project $i$

$W_{K}(t, i)$ : after-tax asset price of capital equipment relative to materials at $t$ for project $i$;

$X(i)$ : dummy variable for project $i$ (= 1 for open-pit operations; $=0$ for underground operations; constant over the waiting period);

$\alpha(t)$ and $\sigma(t)$ : drift $\left(=\alpha_{p}(t)-\alpha_{w}(t)\right)$ in the after-tax price of copper relative to materials, and its variance parameter, as estimated at $t$ (see text);

$\delta(t)$ : discount rate $\left(=r(t)-\alpha_{p}(t)\right)$ applying to revenues at $t$, after correction for the drift $\alpha_{p}$ in real output price;

$\gamma$ : rate of neutral technological change (assumed constant);

$\rho(t)$ : discount rate $\left(=r(t)-\alpha_{w}(t)\right)$ applying to variable costs at $t$, after correction for the real rate of growth $\alpha_{w}(t)$ common to the four factor of production prices (in practice $\left.\alpha_{w}(t)=0\right)$

$\rho_{f}(t)$ : risk free discount rate applying to variable costs at $t\left(=r_{f}(t)-\alpha_{w}(t)\right)$. 


\section{Variables construction and sources}

(except where stated otherwise, all prices are Canadian prices expressed as index numbers $(1971=100))$

OUTPUT PRICE [1940-1980]

The New York Stock Exchange nominal price index of one metric ton of copper, converted into Canadian dollars [(XII) and (VI), Series B3400], and multiplied by the appropriate tax parameter (source below).

ESTIMATED PARAMETERS OF THE OUTPUT PRICE PROCESS: DRIFT AND VARIANCE

The estimation of the drift parameter of the Brownian geometric process is explained in Section 4.2. The variance parameter $\sigma(t)$ was obtained by regressing $\hat{\xi}(\tau)^{2}$ on $P(\tau)^{2}$, over the period $t-14 ; t$, where $\hat{\xi}(\tau)$ is the residual from the OLS estimation of $(19)$ over $t-14 ; t$. There are 26 such periods $(1940-1954 ; 1966-1980) ; t$ statistics ranged from .90 to 5.00 .

VARIABLE INPUT PRICES [1940-1980] (all prices are multiplied by the appropriate tax parameter (source below))

Nominal wage rate: Index number of average wage rates for mining [(VIII), Series E201 rebased for the period 1940-1975, and (IX) for the period 1976-1980];

Nominal energy price: Törnqvist price index based on natural gas, electricity, and crude oil for the manufacturing, mining, and electric power industries. Shares are defined as value shares; prices are defined as value $\div$ quantity. Data come from (VIII, Series Q31and Q32 for gas, Series Q104 and Q109 for electricity, and Series Q19 and Q20 for oil), and the corresponding series from (VII);

Nominal price of materials: general wholesale price index excluding gold [(VIII) for the period 1940-1975, Series K33-43 (rebased) and (I) for the period 1976-1980, Series D500000].

NOMINAL ASSET PRICE OF CAPITAL [1940-1980]

Implicit price indexes of Gross National Expenditures: new machinery and equipment [(VIII), Series K181, for the period 1940-1975, and (I), Series D40639, for the period 1976-

1980], multiplied by the appropriate tax parameter (source below);

RATE OF GROWTH OF FACTOR PRICES

The rate of growth in the share-weighted index of factor prices was so close to that of the general price index that we set $\alpha_{w}=0$.

TAX PARAMETERS [1960-1980]

All tax parameters correspond to the post tax holiday period [(III) for the formulas and (IV) for the the computations].

RATES OF RETURN [1957-1980]

The risk-free rate of return is measured as the Canadian 90-day Treasury Bill rate [(VIII), Series J471, for the period 1954-1977; (VI), Series B14001, for the period 1971-1980]. The risk-adjusted rate of return is based on an unconditional CAPM. It is defined as the sum of i) the Canadian 90-day Treasury Bill real rate, ii) the market risk premium, and iii) an additional premium accounting for the long term nature of the investment, and measured as the difference between the Long term Canada bond rate [(VIII), Series J475, for the period 1954-1977; (VI), Series B14013, for the period 1971-1980]), and the Canadian 90-day Treasury bill rate [(VIII), Series J471, for the period 1954-1977; (VI), Series B14001, for the period 1971-1980]. The risk premium is $\beta\left[\tilde{r}-r_{f}\right]$, where $\beta$ is the (constant) market beta for Canadian metal mines. Since data on the metal mining industry rates of return are available only since 1967 in Canada and given the empirical evidence of (at least partial) integration of Canadian and US stock exchanges (Koutoulas and Kryzanowski, 1994), we used US data to estimate Canadian metal mines market beta's (risk-free rate: US 3-Months Treasury Bills [(X), Series X451, for the period 1957-1970; (XI), for the period 1971-1980)]; rate of return in the metal mining industry and market rate of return: based on Share prices and dividends from Standard \& Poors [(V), average of high and low yearly values]). Nominal rates were corrected for the Canadian rate of inflation (growth rate of the Implicit Deflator of $G D P[(\mathrm{VI})]$. We used the risk-adjusted rate of return as discount rate.

RATE OF TECHNICAL CHANGE 
Given the substantial rate of productivity regress experienced by the industry, we experienced with rates ranging between $-1 \%$ and $-7 \%$, and selected $-6 \%$ as our prefered value based on the likelihood of the price model (see text).

RESERVES, ORE GRADE, CAPACITY, AND EXTRACTION MODE: [II]

Reserves are proven or probable and expressed in thousands of metric tons; grade is a percentage rate by weight; capacity is in metric tons of ore per day; the extraction mode is $X=1$ for open-pit mining and $X=0$ for underground extraction.

\section{REFERENCES}

\section{Data Sources:}

I- Bank of Canada Review; Quarterly, Various Issues, Ottawa.

II- Canadian Mines Handbook, Various Issues, Northern Miner Press Ltd., Toronto.

III- Castonguay, A. (1984); Un Modèle à Capital Putty Clay pour Estimer l'Impact de la Fiscalité sur le Choix de Capacité des Mines au Canada: 1960-1980, Unpublished MA Essay, Department of Economics, Université de Montréal.

IV- Harchaoui, T.M. (1990); Banque de Données pour l'Estimation de l'Impact de la Fiscalité sur le Choix de Capacité des Mines au Canada: 1960-1980, Manuscript.

V- Standard \& Poors Composite-500 Stocks and Metals-Miscellaneous, New York.

VI-Statistics Canada; Canadian Economic Observer, Historical Statistical Supplement 1990/91, \#11-210, Ottawa.

VII- Statistics Canada; Consumption of Purchased Fuel and Electricity by the manufacturing, mining, and electric power industries, Various Issues, \#57-208, Ottawa.

VIII-Statistics Canada; Historical Statistics of Canada, Second Edition, F.H. Leacy Editor, 1983, Ottawa.

IX-Statistics Canada; Revue Générale sur les Industries Minérales, Various Issues, \#26-201, Ottawa.

X- US Department of Commerce, Bureau of the Census; Historical Statistics of the United States, Part 2, Bicentennial Edition, Washington, D.C.

XI- US Department of Commerce, Bureau of the Census; Statistical Abstract of the United States, Various Issues, Washington, D.C. D.C.

XII- World Bank; Commodity Trade and Price Trends, Various Issues, Washington, Article

Koutoulas, G. and Kryzanowski, L. (1994); Integration or Segmentation of the Canadian Stock Market: Evidence Based on the APT, Canadian J. of Econ. 27: 329-51. 


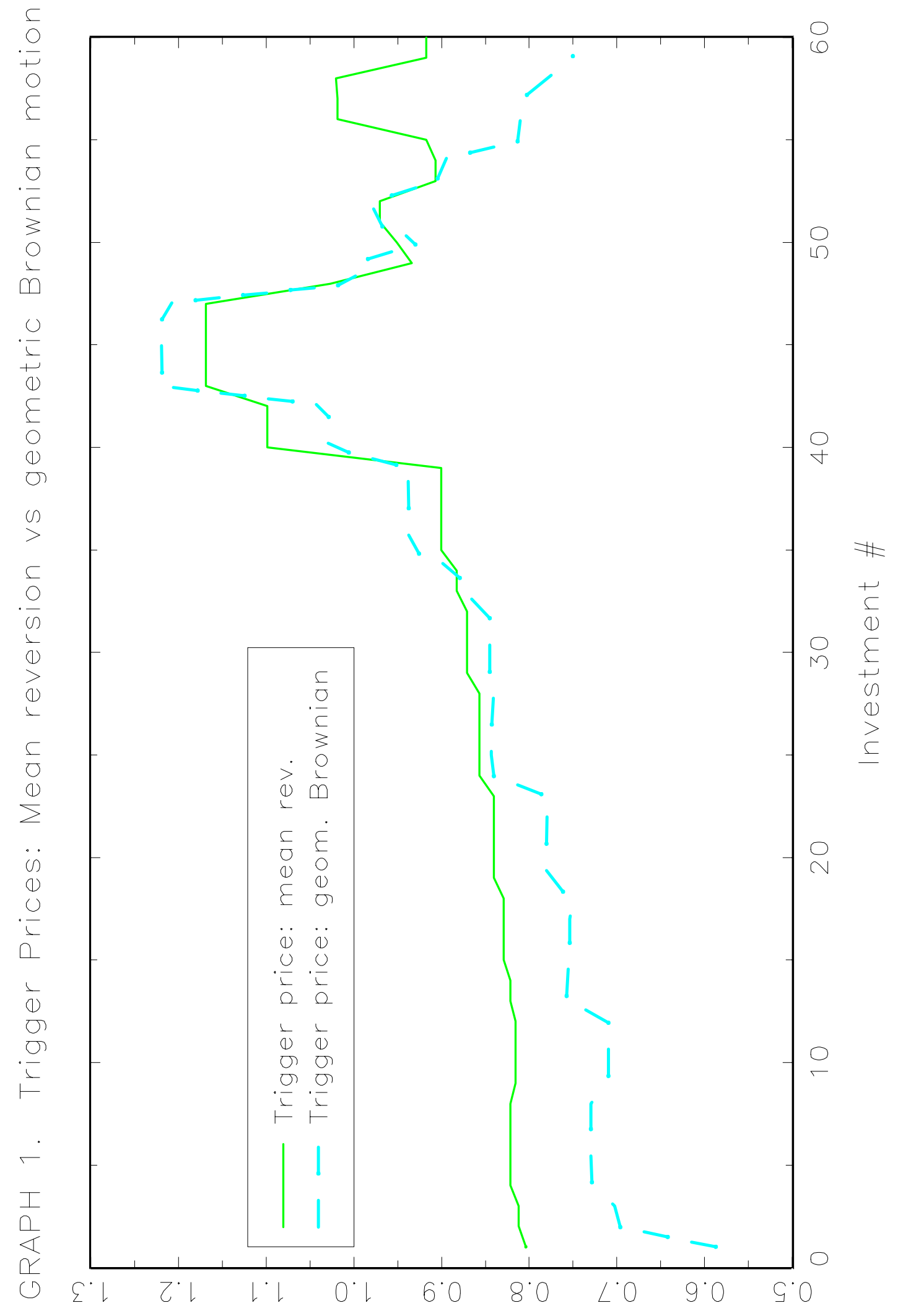




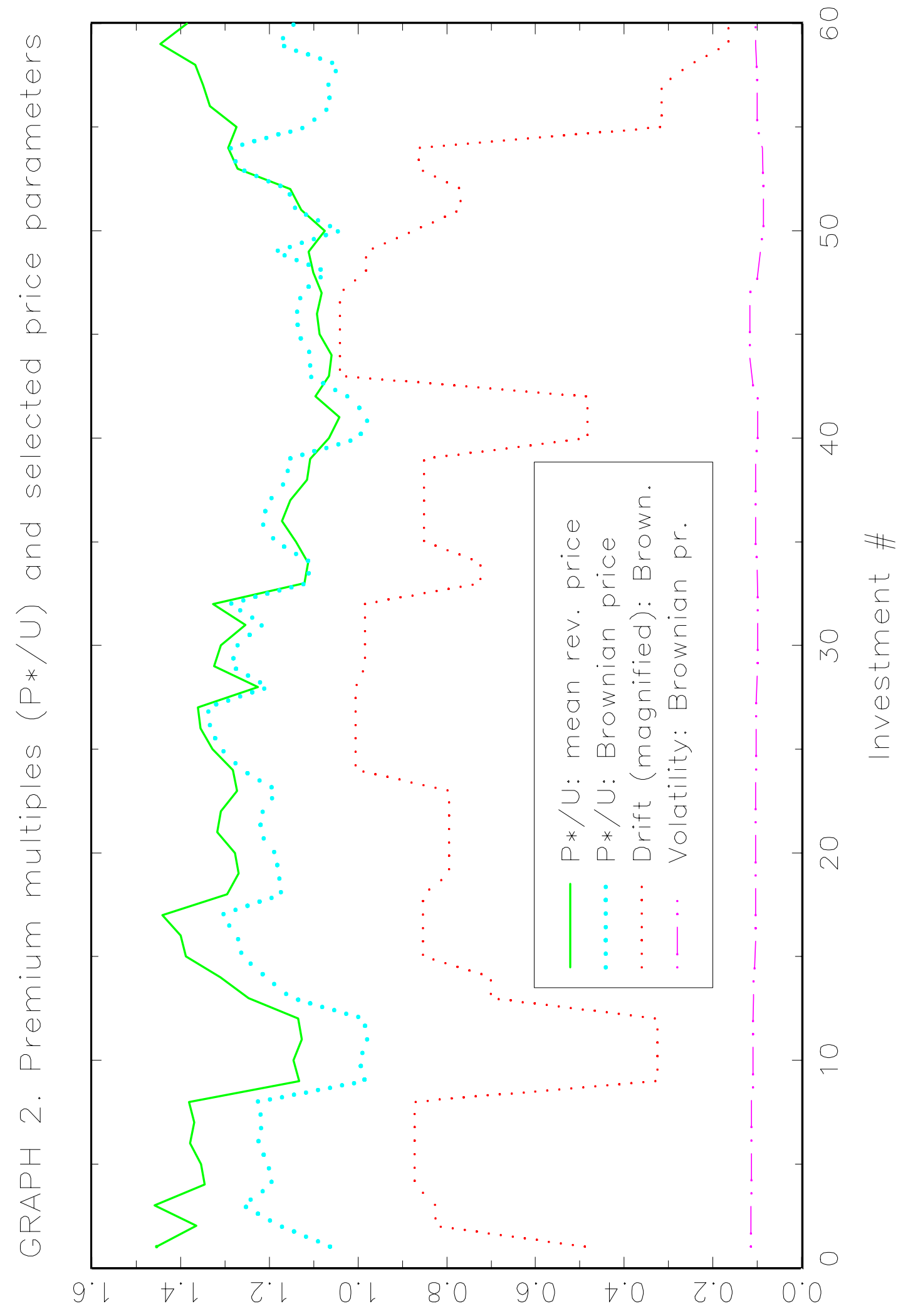


Table 1: Capacity and Exercise Price Models ${ }^{\mathrm{a}}$

\begin{tabular}{|c|c|c|c|c|c|c|c|c|}
\hline Dept. Var. & \multicolumn{3}{|c|}{$\operatorname{Ln} Q^{*}$} & \multicolumn{5}{|c|}{$\operatorname{Ln} P^{*}$} \\
\hline & & & & & $3 \%$ & & $\gamma=-6 \%$ & \\
\hline & Two-stage & estimation & One-st. est. & Two-stage & estimation & & stage estim & ions \\
\hline Expl. Var. & $\begin{array}{c}\text { First stage } \\
\text { Probit } \\
\text { Col. \#2 }\end{array}$ & $\begin{array}{c}\text { Sec. stage } \\
\text { OLS } \\
\text { Col. \#3 }\end{array}$ & $\begin{array}{c}\text { OLS } \\
\text { Col. \#4 }\end{array}$ & $\begin{array}{c}\text { First stage } \\
\text { Probit } \\
\text { Col. \#5 }\end{array}$ & $\begin{array}{c}\text { Sec. stage } \\
\text { OLS } \\
\text { Col. \#6 }\end{array}$ & $\begin{array}{c}\text { First stage } \\
\text { Probit } \\
\text { Col. \#7 }\end{array}$ & $\begin{array}{c}\text { Sec. stage } \\
\text { OLS } \\
\text { Col. \#8 }\end{array}$ & $\begin{array}{c}\text { red'd form } \\
\text { (sec. stage } \\
\text { OLS) } \\
\text { Col. \#9 }\end{array}$ \\
\hline Constant & $\begin{array}{l}-4.89 \\
(-.88) \\
\end{array}$ & $\begin{array}{l}-1.00 \\
(-.97) \\
\end{array}$ & (1.50) & $\begin{array}{l}-2.16 \\
(-.74)\end{array}$ & $\begin{array}{l}.34 \\
(.70)\end{array}$ & $\begin{array}{l}-3.08 \\
(-.81)\end{array}$ & (.14 & $\begin{array}{c}.71 \\
(.48)\end{array}$ \\
\hline $\operatorname{LnP}$ & $\begin{array}{c}-.33 \\
(-.27) \\
\end{array}$ & $\begin{array}{c}1.31 \\
(1.70)\end{array}$ & $\begin{array}{c}1.18 \\
(1.93)\end{array}$ & - & - & - & - & - \\
\hline $\operatorname{Ln} Q^{*}$ & - & - & - & $\begin{array}{l}.45 \\
(.38)\end{array}$ & $\begin{array}{c}.76 \\
(3.32)\end{array}$ & $\begin{array}{l}.99 \\
(.80)\end{array}$ & $\begin{array}{c}.89 \\
(3.96)\end{array}$ & - \\
\hline Mills ratio & - & $\begin{array}{l}.04 \\
(.09)\end{array}$ & - & - & $\begin{array}{c}-.32 \\
(-1.72)\end{array}$ & - & $\begin{array}{c}-.30 \\
(-1.58)\end{array}$ & $\begin{array}{l}-.47 \\
(-5.48)\end{array}$ \\
\hline $\operatorname{Ln} B$ & $\begin{array}{l}-1.01 \\
(-.19)\end{array}$ & - & - & $\begin{array}{l}-3.64 \\
(-1.87)\end{array}$ & $\begin{array}{c}-.87 \\
(-2.81)\end{array}$ & $\begin{array}{l}-7.12 \\
(-1.56)\end{array}$ & $\begin{array}{c}-1.64 \\
(-3.06)\end{array}$ & $\begin{array}{l}.78 \\
(.48)\end{array}$ \\
\hline$L n W_{l}$ & $\begin{array}{c}-1.87 \\
(-1.04)\end{array}$ & $\begin{array}{c}-1.21 \\
(-1.04)\end{array}$ & $\begin{array}{l}-1.08 \\
(-1.20)\end{array}$ & $\begin{array}{l}2.25 \\
(.99)\end{array}$ & $\begin{array}{l}1.25 \\
(2.60)\end{array}$ & $\begin{array}{c}2.91 \\
(1.26)\end{array}$ & $\begin{array}{l}1.38 \\
(2.85)\end{array}$ & $\begin{array}{l}.55 \\
(.89)\end{array}$ \\
\hline$L n W_{E}$ & $\begin{array}{l}.47 \\
(.42)\end{array}$ & $\begin{array}{l}1.18 \\
(.42)\end{array}$ & $\begin{array}{l}1.17 \\
(1.67)\end{array}$ & $\begin{array}{l}-1.59 \\
(-1.14)\end{array}$ & $\begin{array}{c}-1.14 \\
(-4.50)\end{array}$ & $\begin{array}{c}-2.07 \\
(-1.35)\end{array}$ & $\begin{array}{l}-1.25 \\
(-4.93)\end{array}$ & $\begin{array}{l}-.55 \\
(-1.71)\end{array}$ \\
\hline$L n W_{K}$ & $\begin{array}{l}-.13 \\
(-.49)\end{array}$ & $\begin{array}{c}.16 \\
(1.70)\end{array}$ & $\begin{array}{l}0.16 \\
(1.84)\end{array}$ & $\begin{array}{l}.14 \\
(.36)\end{array}$ & $\begin{array}{c}-.08 \\
(-1.48)\end{array}$ & $\begin{array}{l}.06 \\
(.15)\end{array}$ & $\begin{array}{c}-.10 \\
(-1.92)\end{array}$ & $\begin{array}{l}.04 \\
(.51)\end{array}$ \\
\hline $\operatorname{Ln} \alpha^{b}$ & $\begin{array}{l}.02 \\
(.03)\end{array}$ & $\begin{array}{c}-.28 \\
(2.35)\end{array}$ & $\begin{array}{c}-.25 \\
(-1.78)\end{array}$ & $\begin{array}{c}-.65 \\
(-1.43)\end{array}$ & - & $\begin{array}{c}-.69 \\
(-1.24)\end{array}$ & - & $\begin{array}{l}.15 \\
(.64)\end{array}$ \\
\hline $\operatorname{Ln} \rho^{b}$ & $\begin{array}{l}27.83 \\
(2.54)\end{array}$ & $\begin{array}{l}-2.13 \\
(-.29)\end{array}$ & - & - & - & - & - & $\begin{array}{c}-.03 \\
(-1.88)\end{array}$ \\
\hline $\operatorname{LnR}$ & $\begin{array}{l}-.03 \\
(-.51)\end{array}$ & $\begin{array}{c}.63 \\
(9.03)\end{array}$ & $\begin{array}{c}.63 \\
(24.14)\end{array}$ & $\begin{array}{l}-.23 \\
(-.31)\end{array}$ & $\begin{array}{l}-.47 \\
(-3.17)\end{array}$ & $\begin{array}{l}-.57 \\
(-.73)\end{array}$ & $\begin{array}{c}-.55 \\
(-3.81)\end{array}$ & $\begin{array}{l}.02 \\
(.76)\end{array}$ \\
\hline$X$ & $\begin{array}{l}.08 \\
(.35)\end{array}$ & $\begin{array}{c}-.15 \\
(-1.58)\end{array}$ & $\begin{array}{c}-.15 \\
(-1.68)\end{array}$ & $\begin{array}{l}-.02 \\
(-.07)\end{array}$ & $\begin{array}{c}.09 \\
(1.44)\end{array}$ & $\begin{array}{c}.07 \\
(.23)\end{array}$ & $\begin{array}{c}.12 \\
(1.87)\end{array}$ & $\begin{array}{c}-.03 \\
(-.38)\end{array}$ \\
\hline $\operatorname{Ln} G$ & $\begin{array}{l}.11 \\
(.72)\end{array}$ & $\begin{array}{l}-.11 \\
(-.72)\end{array}$ & $\begin{array}{c}-.11 \\
(-1.90)\end{array}$ & $\begin{array}{l}-.03 \\
(-.15)\end{array}$ & $\left(\begin{array}{l}07 \\
(1.46)\end{array}\right.$ & $\begin{array}{l}.04 \\
(.17)\end{array}$ & $(1.98)$ & $\begin{array}{l}-.03 \\
(-.57)\end{array}$ \\
\hline$s^{b}$ & $\begin{array}{c}.14 \\
(1.64)\end{array}$ & - & - & $\begin{array}{l}-.05 \\
(-.62)\end{array}$ & $\begin{array}{l}-.01 \\
(-.64)\end{array}$ & $\begin{array}{l}-.04 \\
(-.57)\end{array}$ & $\begin{array}{l}-.01 \\
(-.55)\end{array}$ & $\begin{array}{c}-.01 \\
(-.43)\end{array}$ \\
\hline $\mathbf{R}^{2} /$ \# of obs. & $-/ 268$ & $.95 / 60$ & $.95 / 60$ & $-/ 268$ & .99 / 60 & $-/ 268$ & $.99 / 60$ & $.95 / 60$ \\
\hline Loglikelihood & -131.75 & -18.11 & -18.30 & -134.61 & 269.25 & -135.43 & 281.72 & 112.43 \\
\hline
\end{tabular}

${ }^{\mathrm{a}} t$-statistics are between parentheses. For the second-stage price equations, the standard errors of the parameter estimates are based on Maddala (pp. 253-56).

${ }^{\mathrm{b}}$ Omitted when not marginally significant. 


\section{Liste des publications au CIRANO *}

\section{Cahiers CIRANO / CIRANO Papers (ISSN 1198-8169)}

99c-1 Les Expos, l'OSM, les universités, les hôpitaux : Le coût d'un déficit de 400000 emplois au Québec — Expos, Montréal Symphony Orchestra, Universities, Hospitals: The Cost of a 400,000-Job Shortfall in Québec / Marcel Boyer

96c-1 Peut-on créer des emplois en réglementant le temps de travail ? / Robert Lacroix

95c-2 Anomalies de marché et sélection des titres au Canada / Richard Guay, Jean-François L'Her et Jean-Marc Suret

95c-1 La réglementation incitative / Marcel Boyer

94c-3 L'importance relative des gouvernements: causes, conséquences et organisations alternative / Claude Montmarquette

94c-2 Commercial Bankruptcy and Financial Reorganization in Canada / Jocelyn Martel

94c-1 Faire ou faire faire : La perspective de l'économie des organisations / Michel Patry

\section{Série Scientifique / Scientific Series (ISSN 1198-8177)}

99s-34 A Resource Based View of the Information Systems Sourcing Mode / Vital Roy et Benoit Aubert

99s-33 Budget Processes: Theory and Experimental Evidence / Karl-Martin Ehrhart, Roy Gardner, Jürgen von Hagen et Claudia Keser

99s-32 Tax Incentives: Issue and Evidence / Pierre Mohnen

99s-31 Decentralized or Collective Bargaining in a Strategy Experiment / Siegfried Berninghaus, Werner Güth et Claudia Keser

99s-30 Qui veut réduire ses heures de travail? Le profil des travailleurs adhérant à un programme de partage de l'emploi / Paul Lanoie, Ali Béjaoui et François Raymond

99s-29 Dealing with Major Technological Risks / Bernard Sinclair-Desgagné et Carel Vachon

99s-28 Analyse de l'impact productif des pratiques de rémunération incitative pour une entreprise de services : Application à une coopérative financière québécoise / Simon Drolet, Paul Lanoie et Bruce Shearer

99s-27 Why Firms Outsource Their Human Resources Activities: An Empirical Analysis / Michel Patry, Michel Tremblay, Paul Lanoie et Michelle Lacombe

99s-26 Stochastic Volatility: Univariate and Multivariate Extensions / Éric Jacquier, Nicholas G. Polson et Peter E. Rossi

99s-25 Inference for the Generalization Error / Claude Nadeau et Yoshua Bengio

99s-24 Mobility and Cooperation: On the Run / Karl-Martin Ehrhart et Claudia Keser

\footnotetext{
* Vous pouvez consulter la liste complète des publications du CIRANO et les publications elles-mêmes sur notre site World Wide Web à l'adresse suivante : http://www.cirano.umontreal.ca/publication/documents.html
} 